\title{
Sustainable recycling of intact carbon fibres from end-of- service-life composites
}

DOI:

10.1039/C9GC01847F

\section{Document Version}

Accepted author manuscript

Link to publication record in Manchester Research Explorer

\section{Citation for published version (APA):}

Chen, P., Pei, C., Zhu, J., Su, M., \& Xing, F. (2019). Sustainable recycling of intact carbon fibres from end-ofservice-life composites. Green Chemistry, 21(17), 4757-4768. https://doi.org/10.1039/C9GC01847F

\section{Published in:}

Green Chemistry

\section{Citing this paper}

Please note that where the full-text provided on Manchester Research Explorer is the Author Accepted Manuscript or Proof version this may differ from the final Published version. If citing, it is advised that you check and use the publisher's definitive version.

\section{General rights}

Copyright and moral rights for the publications made accessible in the Research Explorer are retained by the authors and/or other copyright owners and it is a condition of accessing publications that users recognise and abide by the legal requirements associated with these rights.

\section{Takedown policy}

If you believe that this document breaches copyright please refer to the University of Manchester's Takedown Procedures [http://man.ac.uk/04Y6Bo] or contact uml.scholarlycommunications@manchester.ac.uk providing relevant details, so we can investigate your claim.

\section{OPEN ACCESS}


Pi-yu CHEN, Chun PEI, Ji-Hua ZHU, Mei-ni SU (Corresponding author), Feng XING, (2019), "Sustainable recycling of intact carbon fibres from end-of-service-life composites", Green Chemistry, 21, 4757 - 4768.

Sustainable recycling of intact carbon fibres from end-of-service-life composites

1 Guangdong Province Key Laboratory of Durability for Marine Civil Engineering, School of Civil

ABSTRACT:

A novel method is developed to reclaim carbon fibres from carbon fabric-reinforced cementitious composites. The method takes advantage of an electrically driven chemical reaction in the presence of an aqueous electrolyte solution and an electrical current. This paper presents an experimental programme to investigate the effects of the applied current density, the sodium chloride and nitric acid concentrations in the solution and the temperatures. Both tensile strengths and interfacial shear strengths of the reclaimed carbon fibres were evaluated. Microstructural analyses on the morphologies of the reclaimed carbon fibres were also performed. The proposed method is simple, environmentally friendly and efficient. This method has no size limits on the recycled composites, which indicates the suitability of this approach for large-scale industrial applications. The reclaimed carbon fibres are found to be intact and believed to contain great commercial values since the recycling process did not damage their strengths or reduce their dimensions.

Keywords: Carbon fabric, Composites; Characterization; Electrochemical recycling

\section{Introduction}

Carbon fibre $(\mathrm{CF})$ is a new kind of inorganic material with a multitude of advantages, such as light weight, high tensile strength, high stiffness, high corrosion resistance, and high temperature tolerance [1-4]. Since the late 1980s, carbon fibre-reinforced polymer (CFRP) plates/sheets have been used with epoxy resin to strengthen reinforced concrete structures in the construction industry in Europe, the US and Japan. Over the last 30 years, epoxy resin has become a popular bonding material due to its excellent bonding strength 
30 [5-8]. However, the CFRP-epoxy resin strengthening system also has disadvantages, such as poor 31 resistances to ageing, corrosion, moisture, heat, peeling, cracking and impacts. Therefore, new inorganic cementitious bonding materials (e.g., cement pastes and mortar) have begun to attract interest from industry, especially in the last decade. The advantages of cementitious materials include excellent corrosion resistances, outstanding mechanical properties, such as high strength and strong toughness, and great bonding characteristics with civil engineering structural materials [9].

The wide application of carbon fabric-reinforced cementitious matrix (C-FRCM) composites (i.e., CF cloths/plates/sheets/meshes embedded in a cementitious matrix) in the industry $[10,11]$ also creates substantial waste disposal issues. Moreover, end-of-service-life (EOSL) C-FRCM composites still contain CFs with high residual strengths and commercial values. Therefore, the recycling and reuse of CFs from EOSL composites not only alleviates the pollution from wastes but also makes full use of the $\mathrm{CFs}$, which has an important economic value and social significance. However, it is difficult to decompose a cementitious matrix and reclaim CFs from these composites. There are a number of studies on recycling techniques for reclaiming CFs from CFRP-epoxy resin waste, including mechanical recycling [12, 13], pyrolysis [14, 15], chemical solvent decomposition [16-19], sub/supercritical chemical recycling [20-22], fluidized-bed processes [23-25] and electrochemical recycling [26, 27]. However, there is no research on CF recovery from C-FRCM composites; this study is the first to propose a recycling method to reclaim CFs from cementitious composites.

In this paper, a new recycling method based on an electrically driven chemical reaction is developed to reclaim CFs from C-FRCM composites. The proposed recycling process occurs in an acidic electrolyte solution with an applied current. During the electrochemical reaction, most of the calcium in the cement paste is dissolved, while the majority of silicon remains in the form of $\mathrm{SiO}_{2} \cdot n \mathrm{H}_{2} \mathrm{O}$ gel, leaving a porous corroded cement paste [28]. Finally, the cementitious material loses mechanical interlocking with $\mathrm{CFs}$; thus, the reclaimed $\mathrm{CFs}(\mathrm{rCFs})$ are obtained. This paper first presents an experimental programme to investigate the effects of current density, sodium chloride $(\mathrm{NaCl})$ concentration in the electrolyte solution, nitric acid $\left(\mathrm{HNO}_{3}\right)$ concentration and temperature on the recycling results. Second, tensile tests and interfacial shear strength (IFSS) tests are performed to assess the qualities of the rCFs. Third, microstructural analyses, including scanning electron microscopy (SEM), atomic force microscopy (AFM) and X-ray photoelectron spectroscopy (XPS), are performed to help understand the 
59 electrochemical reaction mechanism and observe the surface morphologies of the rCFs. The recycling method is optimized regarding the recovery rate and residual strengths of the rCFs based on the experimental results and characterization techniques.

\section{Experimental program}

63

64

\subsection{Materials and specimens}

The CFRP sheets were Hitex-C300 (12k one-way woven cloth with an areal density of $300 \mathrm{~g} / \mathrm{m}^{2}$ ) from the Nanjing Haituo Composite Material Co. LTD. The ordinary Portland cement was PO42.5R grade purchased from China Resources Cement Holdings LTD. The chemical composition and physical properties of cement were listed in Table SI. 1 The silicon powder was from Shanghai Xikeng, and the redispersible powder was DY-5025 from Germany. The chopped CFs in the cementitious matrix were 3 mm long. $\mathrm{NaCl}$ and $\mathrm{HNO}_{3}$ were purchased from the Xilong Chemical Company. The composition of the cementitious matrix is shown in Table 1.

The dimensions of the C-FRCM composite sample were $30 \times 265 \times 5 \mathrm{~mm}$ (width $\times$ length $\times$ thickness), as shown in Fig. 1. The layers of the cementitious matrix were approximately $2 \mathrm{~mm}$ thick. The specimen was divided into three regions: the test region to reclaim CFs, the protected region, which was insulated and waterproof, and the electrical connection region, which was connected to the external power supply. The manufacturing process for the C-FRCM composite specimens was conducted in accordance with industry standards.

\subsection{Experimental parameters}

The variables considered in the electrochemical recycling method include the current density, the $\mathrm{NaCl}$ concentration in the electrolyte, the $\mathrm{HNO}_{3}$ concentration and the temperature. To study the effects of each parameter, two series of experiments were designed in this study. The specimens were labelled according to the reaction conditions. For example, the specimen label "I20S2H3T40" comprises four parts: the first part, "I20", represents the applied current (20 mA, corresponding to $\left.3.33 \mathrm{~A} / \mathrm{m}^{2}\right)$; the second part, "S2", indicates the $\mathrm{NaCl}$ concentration in the electrolyte ( $2 \%$ of the weight of deionized water); the third part, "H3", refers to the $\mathrm{HNO}_{3}$ concentration in the electrolyte $(3 \mathrm{~g} / \mathrm{L})$; and the last part, "T40", indicates the temperature $\left(40^{\circ} \mathrm{C}\right)$ at which the recycling process was performed.

In the first series of tests (Table 2), two current densities (3.33 and $\left.6.67 \mathrm{~A} / \mathrm{m}^{2}\right)$, two $\mathrm{NaCl}$ concentrations (2\% and $3 \%)$ and four $\left(\mathrm{HNO}_{3}\right)$ concentrations $(0,1,3$ and $5 \mathrm{~g} / \mathrm{L})$ were considered. A total 
of 16 reaction conditions were included in the test programme, and three samples were used for each set of reaction conditions. In the second series of tests in the experimental programme (Table 3), the effect of temperature was considered. Two reaction conditions with the best performance were selected from the first series of tests. Therefore, the variables considered in the second series of recycling conditions include (1) two applied current densities $\left(20 \mathrm{~mA}\right.$ and $40 \mathrm{~mA}$, which correspond to $3.33 \mathrm{~A} / \mathrm{m}^{2}$ and 6.67 $\mathrm{A} / \mathrm{m}^{2}$, respectively), (2) one $\mathrm{NaCl}$ concentration (2\%), (3) one $\mathrm{HNO}_{3}$ concentration (3 g/L) and (4) three temperatures $\left(40^{\circ} \mathrm{C}, 60^{\circ} \mathrm{C}\right.$ and $\left.75^{\circ} \mathrm{C}\right)$. A total of six reaction conditions were considered, and three specimens were used for each set of reaction conditions.

\section{$96 \quad 2.3$ Recycling process}

97 The experimental device used for the CF recycling process is shown in Fig. 2. The recycling device consists of four main parts: (1) a DC power supply, which provides current to the system; (2) a cathode and an anode, wherein the specimen was connected to the positive pole of the power supply and a stainless steel plate was connected to the negative pole of the power supply as the cathode with $50 \mathrm{~mm}$ distance between the two electrodes is in the experimental programme; (3) an electrolyte, which consisted of $\mathrm{NaCl}$ and $\mathrm{HNO}_{3}$ solution; and (4) a datalogger, which monitored the voltage changes in the system. The first series of electrochemical reactions at room temperature lasted for 8 days, while the second series

104 of reactions at elevated temperatures lasted for 4 days. Afterwards, the specimens (Fig. 3(a)) were cleaned by loosening the cementitious matrix by pressing holes on the surface of the cementitious matrix (Fig. 3(b)) and flushing with a water pressure of $0.5 \mathrm{MPa}$ for 10 seconds (Fig. 3(c)). The cleaned rCFs are shown in Fig. 3(d).

\section{$108 \quad 2.4$ Mechanical tests of the rCFs}

109 The properties of the rCFs were evaluated based on the voltage monitoring of the recovery process by a 110 datalogger (HIOKI-LR8400, Japanese Nikko electric corporation), the hardness tests of the composites 111 after the electrochemical reactions, the tensile tests of the rCF monofilaments, and the IFSS tests between 112 the rCFs and epoxy resin.

The hardness of the composite plate was tested after the recycling process with a coated pencil

114 [29]. According to the specifications, the composite was kept dry, placed on a flat desk and pressed with the pencil under a load of $7.5 \mathrm{~N}$ at a direction of $45^{\circ}$; the loading rate was $0.5-1 \mathrm{~mm} / \mathrm{s}$. Pencils of

116 different grades from 9B (softest level) to 9H (hardest level) were pressed onto the composite surface. 
117 The hardness of the composite surface was measured starting from the softest pencil and determined 118 when a visible mark occurred.

119 The tensile strength of a CF monofilament was tested with a UTM-Bionix Standard Toecomp 120 Quasistatic test system. The loading rate in the tensile test was $0.2 \mu \mathrm{m} / \mathrm{s}$, and the CF sample length was 6 $121 \mathrm{~mm}$. According to ISO 11566 [30], a total of 20 samples were tested for each reaction condition. Before 122 testing, the diameter of the CF monofilament was measured with a laser calliper (Changchun Industrial 123 Optoelectronic Technology Co. LTD).

124 The IFSS between a CF monofilament and epoxy resin was determined by the microdroplet test 125 using an HM410 composite interfacial evaluation device (Japanese Tongrong Corporation). Before testing, 126 the diameter of each resin microdroplet was measured by a high-resolution microscope built in the test 127 system. According to previous studies [31], the diameter of the resin microdroplet was $40-80 \mu \mathrm{m}$. A total 128 of five parallel tests were conducted for each reaction condition. The loading rate for the IFSS test was $1290.12 \mathrm{~mm} / \mathrm{min}$.

\section{$130 \quad 2.5$ Instrumentation}

131 The microstructures of the rCFs were analysed by means of SEM, AFM and XPS. The effects of the reaction conditions on the mechanical properties of the $\mathrm{rCFs}$ were explained at a microscopic scale. A

133 Quanta TM 250 FEG scanning electron microscope (FEI company, USA) was used in this study. The scanning environment was in high-vacuum mode, the working distance was approximately $10 \mathrm{~mm}$, and the test acceleration voltage was $20 \mathrm{kV}$. To improve the conductivity of the $\mathrm{CF}$, the sample was first prepared with a gold spray before testing. AFM technology (ICON-PT-PKG, Brooker company, USA) was used to scan the surface topographies of the rCFs. The scanning range of the sample was $4 \mu \mathrm{m} \times 4$ $\mu \mathrm{m}$, as suggested by Guo [32], and the scanning speed was $1.0 \mathrm{~Hz}$. NanoScope Analysis 1.8 was used to analyse the images and quantify the $\mathrm{rCF}$ surface roughness.

The XPS technology (ULVAC-PHI VPII photoelectron spectrometer) was used to analyse the type

141 and content of the elements and functional groups on the surfaces of the rCFs. Using the XPS Peak 4.1 software, the results were fitted with a Gaussian function and a Lorentz function to obtain the information

143 of the functional groups. The X-ray source of the monochromator was an $\mathrm{Al}$ target. The rCFs were scanned in full spectrum before $\mathrm{C}_{1 \mathrm{~s}}$ was scanned in a high-resolution narrow spectrum. The incident angle was $90^{\circ}$. 
147 In this part, the effects of the current density, $\mathrm{NaCl}$ concentration, $\mathrm{HNO}_{3}$ concentration and temperature

148 on the CF recovery are discussed from the perspectives of system voltage, recycling amount, mechanical 149 properties and microstructures of the rCFs.

\section{$150 \quad 3.1$ System voltage}

151 During the electrochemical recycling process, the measured voltages under different reaction 152 environments were generally stable, as shown in Fig. 4(a). In general, the voltages of the recycling system under a $40 \mathrm{~mA}$ current were larger than those under a $20 \mathrm{~mA}$ current. The voltages under an $\mathrm{NaCl}$

154 concentration of $3 \%$ were larger than those under an $\mathrm{NaCl}$ concentration of $2 \%$. The voltages of the reaction condition without $\mathrm{HNO}_{3}$ were found to be higher than those under the reaction conditions with $\mathrm{HNO}_{3}$. These phenomena can be explained by the slow degradation of the cementitious matrix in the absence of $\mathrm{HNO}_{3}$ and the high electrical resistance of the composite. The voltages under the reaction conditions with a high $\mathrm{HNO}_{3}$ concentration (5\%) were also relatively high because both the cementitious matrix and CF were damaged in this environment. The voltages under the reaction conditions where the $\mathrm{HNO}_{3}$ concentrations were either $1 \%$ or $3 \%$ were the lowest among all considered conditions. Under elevated temperature conditions, the measured voltages of all specimens were generally stable during the recycling process. The voltage differences of the specimens under different parameters and conditions were very small, as shown in Fig. 4(b). The voltage fluctuations of the specimens in the I20 series were

164 less than $0.15 \mathrm{~V}$, and those of the specimens in the I40 series were less than $0.10 \mathrm{~V}$. The measured voltages of the specimens at $60^{\circ} \mathrm{C}$ were the lowest, indicating the good electrical conductivity of the system and low damage to the rCFs.

\subsection{Recycling amount}

168 The weight of the virgin $\mathrm{CF}(\mathrm{vCF})$ sheet was $841 \mathrm{mg}$. In the absence of the $\mathrm{HNO}_{3}$ solute, no rCFs were obtained since the composite was still hard and the cementitious matrix could not be removed. As shown in Table 4, in the presence of the $\mathrm{HNO}_{3}$ solute, the number of rCFs increased with increasing $\mathrm{HNO}_{3}$ concentration in the beginning and then decreased. When the $\mathrm{HNO}_{3}$ concentration was $3 \mathrm{~g} / \mathrm{L}$, the greatest

172 number of rCFs was collected, and the current densities and $\mathrm{NaCl}$ concentrations had limited influences on the results. The greatest number of $\mathrm{rCFs}$ was collected at a reaction temperature of $40^{\circ} \mathrm{C}(91.8 \%$ of the

$174 \mathrm{vCFs}$ ). Note that the length of the recycling process under a high temperature was only half of that at 
176 high temperatures had beneficial effects on the chemical reclamation of CFs. At the same temperature, a

177 greater number of rCFs was collected under a $20 \mathrm{~mA}$ current than under a $40 \mathrm{~mA}$ current.

\section{$178 \quad 3.3$ Mechanical properties}

179 The hardness values of the degraded C-FRCM composites after electrochemical recycling at either room 180 temperature or higher temperatures are shown in Table 4. The concentration of the $\mathrm{HNO}_{3}$ solute had the 181 most substantial influence on the hardness, wherein the higher the concentration is, the more extensive the degradation and the lower the hardness value. Under the same concentration of the $\mathrm{HNO}_{3}$ solute, a larger

$183 \mathrm{NaCl}$ concentration and current resulted in a softer specimen surface. In the absence of the $\mathrm{HNO}_{3}$ solute, the composite was only partly softened. The hardness of the treated composite directly affected the number of rCFs because it was easier to clean and collect a greater number of rCFs in the softer specimens. Temperature plays an important role in the degradation of the cementitious matrix. Similar to the findings at room temperature, the lower hardness values resulted in a greater number of rCFs. indicating that the rCFs had not been substantially degraded in the electrochemical recovery process. The tensile strengths of the rCFs are shown in Table 5 (also refer to Fig. SI2, SI3, Table SI2, SI3 and SI4). The tensile strength of the vCF was $3.58 \mathrm{GPa}$. The residual tensile strengths of the rCFs decreased as the $\mathrm{HNO}_{3}$ concentration increased, indicating that the presence of $\mathrm{HNO}_{3}$ might cause unfavourable degradation in the rCFs. The current density and $\mathrm{NaCl}$ concentration had limited effects on the tensile strengths of the rCFs. The diameters of the rCF filaments were found to be $7 \mu \mathrm{m}$, which were the same as those of the rCFs obtained at room temperature. The tensile strengths of the rCFs showed an increasing trend with increasing temperature. Generally, the tensile strengths of the CFs reclaimed under the $20 \mathrm{~mA}$ current condition were higher than those reclaimed under the $40 \mathrm{~mA}$ current condition. The highest residual tensile strength of the rCF was found to be $3.21 \mathrm{GPa}$ (specimen I20S2H3T75), which was 89.58\% of tensile strength of the vCF. The roughness values of the rCFs measured by AFM and the IFSS values between the rCFs and epoxy resin are shown in Table 5 and Fig. 8. When the temperature was $40^{\circ} \mathrm{C}$, the rCFs were only slightly affected by the electrochemical reaction (Fig. 8(c)), and the roughness of the $\mathrm{rCF}$ was $134 \mathrm{~nm}$, which is similar to the roughness of the $\mathrm{vCF}(144 \mathrm{~nm})$. Thus, the IFSS values of 
$204\left(105.02 \%\right.$ of the IFSS of the vCF). As the temperature continued to increase to $60^{\circ} \mathrm{C}$, the grooves on the 205 surfaces of the rCFs became deeper and more pronounced; in addition, both the amount and size of the 206 convex hills increased (Fig. 8(d)). The roughness of the $\mathrm{rCF}$ at $60^{\circ} \mathrm{C}$ was found to be $168 \mathrm{~nm}$. The 207 changes in the topographies of the rCFs enhance the mechanical interlocking between the CFs and epoxy 208 resin. The specimen I20S2H3T60 had the greatest IFSS value at $60^{\circ} \mathrm{C}$. When the temperature reached $20975^{\circ} \mathrm{C}$, the grooves widened (Fig. 8(e)), and the roughness increased to $184 \mathrm{~nm}$. However, the IFSS 210 decreased under this condition. This decreasing phenomenon occurs due to the decreased mechanical 211 bonding resulting from significant changes in the surface topography and the degraded chemical bonding 212 resulting from fewer strong-hydrophilic group $\mathrm{O}-\mathrm{C}=\mathrm{O}$ bonds. In the IFSS tests, the failure modes of all specimens were debonding at the resin layer (DB) except specimen I40S2H3T60, whose failure mode was debonding at the interface between the CFs and the matrix (CB). Therefore, the IFSS between rCF and epoxy resin is one of the assessment criteria used for rCFs. Table 5 shows the IFSS between rCF and epoxy resin, and Fig. 7 shows the failure modes, which were observed via SEM. The IFSS between the vCF and epoxy resin was found to be $27.09 \mathrm{MPa}$, and the failure mode was DB (Fig. 7(a)). Generally, the IFSS values between the rCFs and epoxy resin decreased with increasing $\mathrm{HNO}_{3}$ concentration. In the presence of a low concentration of $\mathrm{HNO}_{3}$ (i.e., $1 \mathrm{~g} / \mathrm{L}$ and $3 \mathrm{~g} / \mathrm{L}$ ), the IFSS between the rCF and epoxy resin was greater than that between the vCF and epoxy resin. When the $\mathrm{HNO}_{3}$ concentration was $1 \mathrm{~g} / \mathrm{L}$ and $3 \mathrm{~g} / \mathrm{L}$, smaller current densities and lower $\mathrm{NaCl}$ concentrations had positive effects on the rCFs. When the concentration of $\mathrm{HNO}_{3}$ was $1 \mathrm{~g} / \mathrm{L}$, the failure mode of the $\mathrm{rCF}$ was similar to that of the $\mathrm{vCF}$, which was a DB failure with a thin layer of epoxy resin on the surface of the rCF. The results indicate that the interface between the CF and epoxy resin was stronger than that between the epoxy resin layer. When the concentration of $\mathrm{HNO}_{3}$ became $3 \mathrm{~g} / \mathrm{L}$, a CB failure was observed (Fig. 7(b)), showing that the weakest part of the specimen was the interface between the CF and epoxy resin. However, the IFSS values of the H3 series of specimens were still higher than that of the vCF, which might be attributed to the needle-like resin structures on the fracture surfaces. The needle-like structures could increase the contact area and roughness of the interfacial region between the CF and epoxy resin [36], thus leading to a greater IFSS. 
233 SEM scanning was performed on a cementitious matrix to explore the degradation mechanism of the 234 cementitious matrix during the electrochemical reaction. Fig. 5(a) shows the interface between cementitious materials and CF in the virgin specimen. The ribbed groove structures with regular shapes and some interpenetrating networks formed by the cement slurry and polymer throughout the structures were observed, which are similar to those found in the literature $[37,38]$. These structures formed strong mechanical interlocking with CFs. The interface of the cementitious matrix and CF was changed after the electrochemical reaction (Fig. 5(b)). The diamond shape groove structure was cut off by large vertical and horizontal cracks into small broken units, and the porosity of the material was increased dramatically.

241 Therefore, the interfacial mechanical interlocking between the cementitious matrix and CF was weakened.

242 Some white colour products formed at the interface, which was speculated to be $\mathrm{SiO}_{2}$ gel degraded from

243 C-S-H gel $[28,39]$. The mechanism can be explained by the leaching of $\mathrm{Ca}^{2+}$ ions in the cement matrix

244 during electrochemical reaction, leading to the dissolution of $\mathrm{Ca}(\mathrm{OH})_{2}$ and calcium sulphoaluminates.

245 Porous structure formed after the decalcification of C-S-H in cement paste [28]. The CF was thus isolated

246 from the cement matrix. A typical SEM image of $\mathrm{rCF}$ reclaimed at high temperature condition is

247 presented in Fig. 6(c) (Fig. SI6). The surface of rCFs reclaimed at high temperature was rather clean

248 without visible cement gel particles and defects, which were different from rCFs reclaimed under room

249 temperature (Fig. 6(b)). The reason may be that the recycling process under the high temperatures was

250 shortened, which effectively reduced the degradation (oxidation and acidification, etc.) of rCFs.

Two typical pictures of the vCFs and rCFs (from specimen I40S2H3) are presented in Fig. 6. The surfaces of the vCFs were rather smooth without visible defects (Fig. 6(a)). The surfaces of the rCFs had some cement gel particles and clear longitudinal and horizontal cracks (Fig. 6(b)). The SEM images show

254 the degradation of the rCFs, which explains the decrease in the residual tensile strength. In addition, the rCFs obtained under $20 \mathrm{~mA}$ current conditions had fewer defects compared to those obtained under 40 $\mathrm{mA}$ current conditions, indicating that the degradation of the CFs was caused by large currents.

Fig. 8 shows two typical AFM images of the vCFs and rCFs. The surfaces of the $\mathrm{vCF}$ were smooth and neat (Fig. 8(a)), whose roughness was found to be $144 \mathrm{~nm}$. Due to oxidation etching during the electrochemical reaction, longitudinal grooves and convex hills along the fibre were formed on the surfaces of the rCFs (Fig. 8(b)). These changes to the fibre geometries significantly enhanced the 
261 mechanical interlocking between the rCFs and epoxy resin, which are similar to the ribs in steel reinforcements used to improve the bonding between reinforcement and concrete. Moreover, the

263 increasing roughness enhanced the bonding between the rCFs and epoxy resin. The relationship between

264 the roughness and IFSS is shown in Fig. 9, wherein the IFSS generally increases as the rCF surface

265 roughness increases. Therefore, rCFs could reach higher IFSS values than vCFs. In summary, when the $\mathrm{HNO}_{3}$ concentration was low, mild oxidation etching during electrochemical recovery had a positive influence on the IFSS; when the $\mathrm{HNO}_{3}$ concentration increased to a certain extent, excessive oxidation etching reduced the IFSS.

The full spectrum of the XPS scan and the high-resolution narrow spectrum of $\mathrm{C}_{1 \mathrm{~s}}$ of the rCFs are shown in Fig. 10. There were five peaks observed in the full spectrum of scanning: the two main peaks were carbon $(\mathrm{C})(284.6 \mathrm{eV})$ and oxygen $(\mathrm{O})(532.0 \mathrm{eV})$, and the three secondary peaks were silicon (Si) $(99.5 \mathrm{eV})$, chlorine $(\mathrm{Cl})(199.8 \mathrm{eV})$ and calcium $(\mathrm{Ca})(347 \mathrm{eV})$. The basic elements on the surfaces of the $\mathrm{rCF}$ s were $\mathrm{C}$ and $\mathrm{O}$, and small amounts of $\mathrm{Si}, \mathrm{Cl}$ and $\mathrm{Ca}$ were introduced during the recycling process. The elemental contents on the surfaces of vCF and rCF (I20S2 series) are shown in Table 6. The carbon and oxygen contents on the surface of the $\mathrm{vCF}$ were $79.3 \%$ and $20.7 \%$, respectively. The carbon content on the rCF surface was approximately $10 \%$ less than that on the vCF surface, while the oxygen content was higher on the rCF surface. When the $\mathrm{HNO}_{3}$ concentration was $3 \mathrm{~g} / \mathrm{L}$, the oxygen/carbon $(\mathrm{O} / \mathrm{C})$ ratio was found to be highest, indicating that in this reaction condition, the most oxygen had been introduced to the surface of the rCF, which led to greater surface activity and enhanced the chemical bonding between the rCF and epoxy resin $[40,41]$.

The XPS Peak 4.1 programme was used to classify the $C_{1 s}$ high-resolution narrow spectrum according to the binding energy into the following six bond peaks for Gaussian-Lorentz fitting: graphite state C-C (284.4 eV), amorphous state C-C (284.8 eV), C=O (285.5 eV), C-O (286.2 eV), C-Cl (287.2 eV) and $\mathrm{O}-\mathrm{C}=\mathrm{O}(288.4 \mathrm{eV})[33,42-44]$. The fitting of the $\mathrm{C}_{1 \mathrm{~s}}$ split peaks is shown in Fig. 10, and the specific contents of the functional groups on the surface of the $\mathrm{rCF}$ are shown in Table 6 . The results revealed that there were more carbon and oxygen-containing functional groups on the surface of the $\mathrm{rCF}$ than on the surface of the vCF. Studies have shown that in electrochemical anodization [34], the activated carbon and oxygen-containing functional groups on the surface of a CF can be gradually oxidized by oxygen atoms or ions: from $\mathrm{C}-\mathrm{O}$ to $\mathrm{C}=\mathrm{O}$ to $\mathrm{O}-\mathrm{C}=\mathrm{O}$. The $\mathrm{CFs}$ reclaimed in this study were oxidized during the recovery 
process, and the surface oxygen content increased, which enabled the surface to be more active. Moreover, the occurrence of hydrophilic $\mathrm{O}-\mathrm{C}=\mathrm{O}$ groups also greatly improved the chemical bonding between the

292 rCFs and epoxy resin. The contents of the elements on the surfaces of the rCFs are shown in Table 6.

293 Compared to the vCF, the content of carbon (C) decreased, and the oxygen (O) content substantially

294 increased. The oxygen/carbon (O/C) ratio was found to be 0.2610 for the $\mathrm{vCF}$ and $0.407-0.429$ for the

295 rCFs. A large amount of active oxygen was incorporated onto the surfaces of the rCFs during the

296 electrochemical process at high temperatures, which led to more oxygen-containing groups on the

297 surfaces of the rCFs and a greater degree of oxidation.

298 The contents of the functional groups of $\mathrm{C}$ on the surfaces of the rCFs are shown in Table 6. The

299 number of strong-hydrophilic group $\mathrm{O}-\mathrm{C}=\mathrm{O}$ bonds decreased at high temperatures because $\mathrm{C}$ tends to

300 generate carbon dioxide and water at high temperatures [35]. This might explain the lower IFSS values of

301 the $\mathrm{rCFs}$ at $75^{\circ} \mathrm{C}$. The experimental results in this study indicated that increasing the temperature could

302 increase the oxidation degree on the surfaces of the rCFs; however, if the temperature exceeds a certain

303 threshold, over-oxidation would lead to a lower amount of rCFs and weaken the chemical bonding

304 between the $\mathrm{CF}$ and cement matrix. In addition, the percentage of $\mathrm{C}-\mathrm{Cl}$ bonds on the surface of specimen

305 I20S2H3T40 was $8.2 \%$ (Table 6), showing that the rCFs obtained from this reaction condition were

306 chlorinated, which resulted in decreased tensile strengths. However, it should be noted that the chlorine

307 on the surfaces of the rCFs from specimens I20S2H3T60 and I20S2H3T75 were not in the chemical

308 bonds (Table 6) but exists only in the adsorption state.

\section{4. Conclusions}

310 A new electrochemical method for recycling CFs from C-FRCM composites was developed in this study.

311 This new method takes advantage of an electrically driven chemical reaction in the presence of an

312 aqueous electrolyte solution and an electrical current. Furthermore, this recycling method used affordable

313 and non-toxic chemicals, small currents and easily implemented facilities to reclaim intact CFs. Tensile

314 tests and IFSS tests were conducted to characterize the rCFs. Microstructural analysis technologies were

315 adopted to understand the mechanisms of the behaviours of the rCFs. The effects of different parameters

316 were investigated by an experimental programme to optimize the recycling process. Experimental results

317 showed that a low current density $\left(3.33 \mathrm{~A} / \mathrm{m}^{2}\right)$ and a low $\mathrm{NaCl}$ concentration (2\%) could improve the

318 electrochemical corrosion of the cement matrix and the tensile strengths of the rCFs. Adding an 
319 appropriate amount of nitric acid $(3 \mathrm{~g} / \mathrm{L})$ can enhance the recycling efficiency and the IFSS values 320 between the rCFs and epoxy resin. Compared to normal temperature conditions, higher temperatures can 321 further improve the recycling efficiency and the tensile strengths of the rCFs. The rCFs and vCFs 322 exhibited similar properties: the residual tensile strengths of the $\mathrm{rCF}$ s were approximately $90 \%$ of that of 323 the vCFs, the IFSS values of the rCFs were $117 \%$ of that of the $\mathrm{vCFs}$, and the recovery of the rCFs was

$32492 \%$. This new recycling method is expected to solve EOSL composite waste problems and fully utilize 325 the residual values of disposed CFs. Because of the high-quality of the rCFs, they can also be used in 326 various applications, ranging from aerospace to ground transportation, construction industries to sporting 327 goods. Compared with traditional recycling methods, this new method is efficient, sustainable, 328 inexpensive, and easily implemented, and the new method has no size limits on the recycled composites.

329 Thus, this new recycling method is suitable for large-scale applications in industry.

\section{Acknowledgements}

331 The authors wish to express their gratitude and sincere appreciation to the National Natural Science Foundation of China $(51861165204,51778370,51538007)$ and Natural Science Foundation of Guangdong (2017B030311004) and the Shenzhen Science and Technology Project (JCY20170818094820689) for financing this research work.

\section{Declarations of interest}

336 None.

\section{References}

338 [1] Park SJ, Kim BJ. Carbon Fibers and Their Composites: Springer Netherlands; 2015.

339 [2] Park SJ, Bae KM. Testing of Carbon Fibers and Their Composites: Springer Netherlands; 2015.

340 [3] Park SJ. Novel Carbon Fibers and Their Composites. Springer. 2018;210:275-317.

341 [4] Zhu J-H, Wei L, Moahmoud H, Redaelli E, Xing F, Bertolini L. Investigation on CFRP as dual342 functional material in chloride-contaminated solutions. Construction and Building Materials. $343 \quad 2017 ; 151: 127-37$.

344 [5] May C. Epoxy resins: chemistry and technology: CRC press; 1987.

345 [6] Czaderski C, Martinelli E, Michels J, Motavalli M. Effect of curing conditions on strength 346 development in an epoxy resin for structural strengthening. Composites Part B: Engineering. $347 \quad 2012 ; 43(2): 398-410$. 
348 [7] Zhou Y, Fan Z, Du J, Sui L, Xing F. Bond behavior of FRP-to-concrete interface under sulfate attack:

349 An experimental study and modeling of bond degradation. Construction and Building Materials. $350 \quad 2015 ; 85: 9-21$.

351 [8] Zhou Y, Hu J, Li M, Sui L, Xing F. FRP-confined recycled coarse aggregate concrete: Experimental 352 investigation and model comparison. Polymers. 2016;8(10):375.

353 [9] ACI. Guide to design and construction of externally bonded fabric-reinforced cementitious matrix

354 (FRCM) systems for repair and strengthening concrete and masonry structures. 2013.

355 [10] Su M, Wei, L, Zhu, J.H., Ueda T., Guo G. and Xing, F. Experimental investigation of the ICCP-SS 356 technique based on the C-FRCM composite. Journal of Composites for Construction, ASCE. 2019; 357 23(4):04019021.

358 [11] Zhu J.H., Su M.N., Huang J.Y., Ueda T, Xing F. The ICCP-SS technique for retrofitting reinforced concrete compressive members subjected to corrosion. Construction and Building Materials. $360 \quad 2018 ; 167: 669-79$.

361 [12] Palmer J, Ghita OR, Savage L, Evans KE. Successful closed-loop recycling of thermoset composites.

362 Composites Part A Applied Science \& Manufacturing. 2009;40(4):490-8.

363 [13] Pickering SJ. Recycling technologies for thermoset composite materials_current status. Composites 364 Part A Applied Science \& Manufacturing. 2006;37(8):1206-15.

365 [14] Nahil MA, Williams PT. Recycling of carbon fibre reinforced polymeric waste for the production of 366 activated carbon fibres. Journal of Analytical \& Applied Pyrolysis. 2011;91(1):67-75.

367 [15] Cunliffe AM, Jones N, Williams PT. Recycling of fibre-reinforced polymeric waste by pyrolysis: 368 thermo-gravimetric and bench-scale investigations. Journal of Analytical \& Applied Pyrolysis. $2003 ; 70(2): 315-38$.

370 [16] Jiang J, Deng G, Chen X, Gao X, Guo Q, Xu C, et al. On the successful chemical recycling of carbon 371 fiber/epoxy resin composites under the mild condition. Composites Science and Technology. $372 \quad 2017 ; 151: 243-51$.

373 [17] Wang Y, Cui X, Ge H, Yang Y, Wang Y, Zhang C, et al. Chemical Recycling of Carbon Fiber

374 Reinforced Epoxy Resin Composites via Selective Cleavage of the Carbon-Nitrogen Bond. Acs Sustainable Chemistry \& Engineering. 2015;3(12). 

composites in molten potassium hydroxide. Polymer Degradation \& Stability. 2015;111:247-56.

378 [19] Li J, Xu PL, Zhu YK, Ding JP, Xue LX, Wang YZ. A promising strategy for chemical recycling of carbon fiber/thermoset composites: self-accelerating decomposition in a mild oxidative system. Green

380 Chemistry. 2012;14(1):3260-3.

381 [20] Piñero-Hernanz R, Dodds C, Hyde J, García-Serna J, Poliakoff M, Lester E, et al. Chemical 382 recycling of carbon fibre reinforced composites in nearcritical and supercritical water. Composites Part A. 2008;39(3):454-61.

384 [21] Piñero-Hernanz R, García-Serna J, Dodds C, Hyde J, Poliakoff M, Cocero MJ, et al. Chemical recycling of carbon fibre composites using alcohols under subcritical and supercritical conditions. Journal of Supercritical Fluids. 2008;46(1):83-92.

387 [22] Bai Y, Wang Z, Feng L. Chemical recycling of carbon fibers reinforced epoxy resin composites in oxygen in supercritical water. Materials \& Design. 2010;31(2):999-1002.

389 [23] Jiang G, Pickering SJ, Walker GS, Wong KH, Rudd CD. Surface characterisation of carbon fibre recycled using fluidised bed. Applied Surface Science. 2008;254(9):2588-93.

391 [24] Pickering SJ, Kelly RM, Kennerley J, Rudd C, Fenwick N. A fluidised-bed process for the recovery of glass fibres from scrap thermoset composites. Composites Science and Technology. 2000;60(4):509-23. [25] Yip HLH, Pickering SJ, Rudd CD. Characterisation of carbon fibres recycled from scrap composites using fluidised bed process. Plastics, Rubber and Composites. 2002;31(6):278-82.

395 [26] Zhu J.H., Chen, P.Y., Su, M.N., Pei, C, Xing, F., Recycling of Carbon Fibre Reinforced Plastics by Electrically Driven Heterogeneous Catalytic Degradation of Epoxy Resin. Green Chemistry. 2019; 21:1635-1647.

398 [27] Sun H, Guo G, Memon SA, Xu W, Zhang Q, Zhu J-H, et al. Recycling of carbon fibers from carbon fiber reinforced polymer using electrochemical method. Composites Part A: Applied Science and Manufacturing. 2015;78:10-7.

401 [28] Shi C, Stegemann JA. Acid corrosion resistance of different cementing materials. Cement \& 402 Concrete Research. 2000;30(5):803-8.

403 [29] IX-ISO. Paints and varnishes - Determination of film hardness by pencil test 2012.

404 [30] IIX-ISO. Carbon fibre-determination of the tensile properties of single-filament specimens. 1996. 
405 [31] Lei C, Zhao J, Zou J, Jiang C, Li M, Zhang X, et al. Assembly Dependent Interfacial Property of 406 Carbon Nanotube Fibers with Epoxy and Its Enhancement via Generalized Surface Sizing. Advanced 407 Engineering Materials. 2016;18(5):839-45.

408 [32] Guo H. Characterization of Surface Energy, Surface Roughness and Chemical Component of Carbon 409 Fibres. PhD thesis, Harbin Institute of Technology. 2009.

410 [33] Tian S, Li L, Sun W, Xia X, Han D, Li J, et al. Robust adhesion of flower-like few-layer graphene 411 nanoclusters. Sci Rep. 2012;2(7):511.

412 [34] Liu HP, Lv C.X., Li, Y.H., Yang, Y., Li, K.X. and He F. Surface properties of electrochemically 413 oxidized PAN-based carbon fibres. New Carbon Materials. 2005;20(1):39-44.

414 [35] Pimenta S, Pinho ST. The effect of recycling on the mechanical response of carbon fibres and their 415 composites. Composite Structures. 2012;94(12):3669-84.

416 [36] Zhang X FX, Yan C, et al. Interfacial microstructure and properties of carbon fibre composites 417 modified with graphene oxide. ACS applied materials \& interfaces. 2012;4(3):1543-52.

418 [37] Y O. Principle of latex modification and some typical properties of latex-modified mortars and 419 concretes adhesion; binders (materials); bond (paste to aggregate); carbonation; chlorides; curing; 420 diffusion. Materials Journal. 1987;84(6):511-8.

421 [38] Isenburg JE, Vanderhoff JW. Hypothesis for Reinforcement of Portland Cement by Polymer Latexes. 422 Journal of the American Ceramic Society. 2010;57(6):242-5.

423 [39] Pavlík V. Corrosion of hardened cement paste by acetic and nitric acids part II: formation and 424 chemical composition of the corrosion products layer. Cement and Concrete research. 1994;24(8):1495425508.

426 [40] Yue Z.R. Jiang W, Wang L., Gardner S.D., PittmanJr. C.U., Surface characterization of 427 electrochemically oxidized carbon fibers. Carbon. 1999;37(11):1785-96.

428 [41] Severini F, Formaro L, Pegoraro M, Posca L. Chemical modification of carbon fiber surfaces. 429 Carbon. 2002;40(5):735-41.

430 [42] Miao L, Feng C, Zhang Z, Lei X, Chen R, Yang Y, et al. Simultaneous reduction of nitrate and 431 oxidation of by-products using electrochemical method. Journal of Hazardous Materials. 432 2009;171(1):724-30. 
433

434

435

436

437

438

439

440

441

442

443

444

445

446

447

448

449

450

451

452

453

454

455

456

457

458

459

460

461

[43] Rajeshwar K IJG. Environmental electrochemistry: Fundamentals and applications in pollution sensors and abatement. Elsevier. 1997.

[44] Heremans J, Rahim I, Dresselhaus MS. Thermal Conductivity and Raman Spectra of Carbon Fibers. Physical Review B Condensed Matter. 1985;32(10):6742-7.

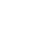

\section{0}

42

3


463 Fig. 1. Dimensions of the C-FRCM specimens

464 Fig. 2. Schematic drawing of the electrochemical reaction system

465 Fig. 3. Specimens after electrochemical reaction and cleaning treatment

466 Fig. 4. System voltage during the electrochemical reaction

467 Fig. 5. SEM images of the interface between the CFs and the cementitious material

468 Fig. 6. SEM images of the rCFs

469 Fig. 7. Failure modes of the IFSS test specimens

470 Fig. 8. Typical AFM morphology images of the rCFs

471 Fig. 9. Relationship between the surface roughness and IFSS

472 Fig. 10. Full spectrum and high-resolution narrow spectrum of the rCFs

473

474

475

476

477

478

479

480

481

482

483

484

485

486

487

488 


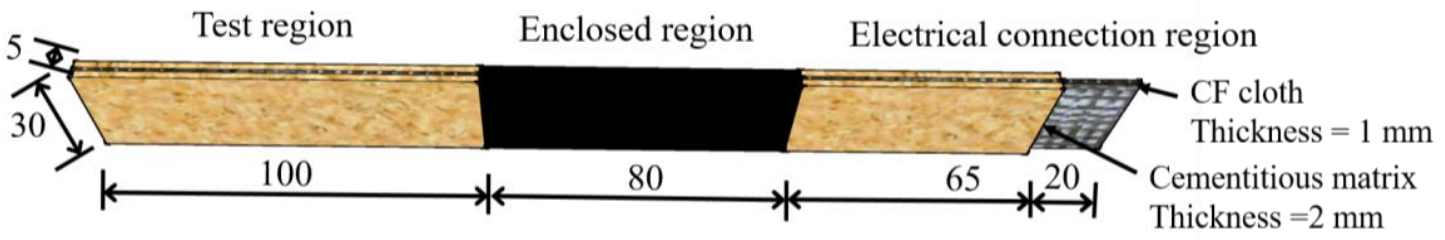

489

490

Fig. 1.

491

492

493

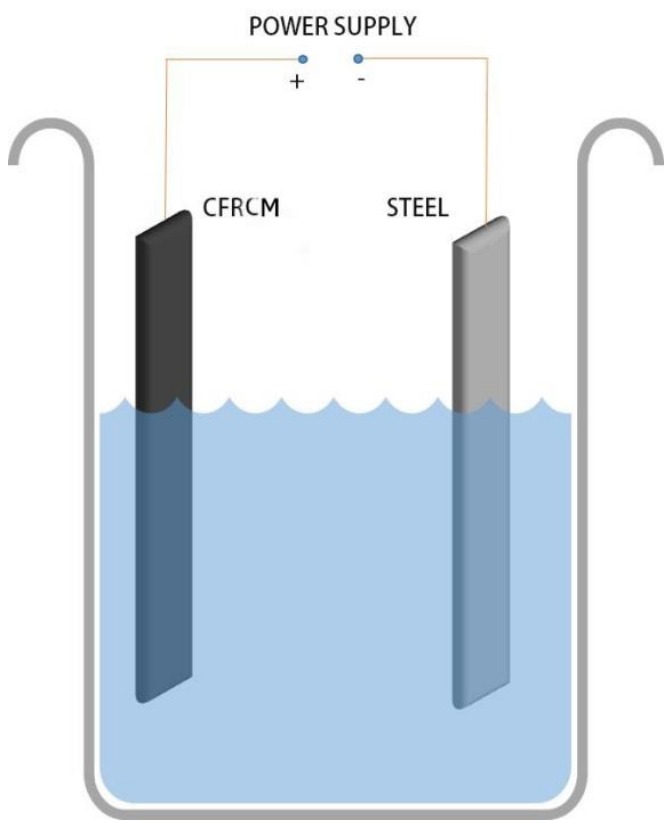

494

Fig. 2.

495

496 
505

506

507

508

509

510

511

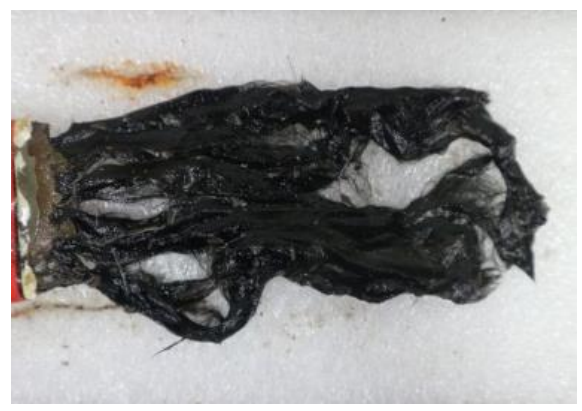

(c) After flushing

Fig. 3.

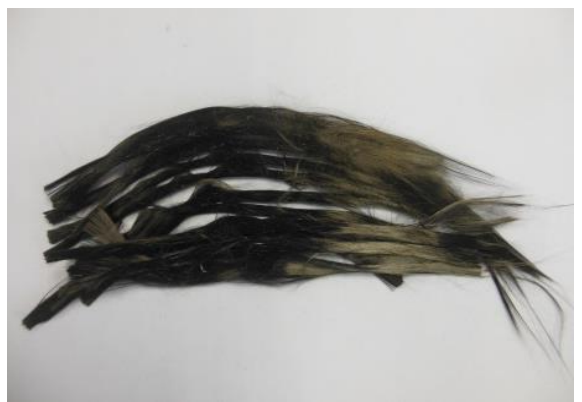

(d) Cleaned rCFs

512

513

514

515

516

517

518

519

520

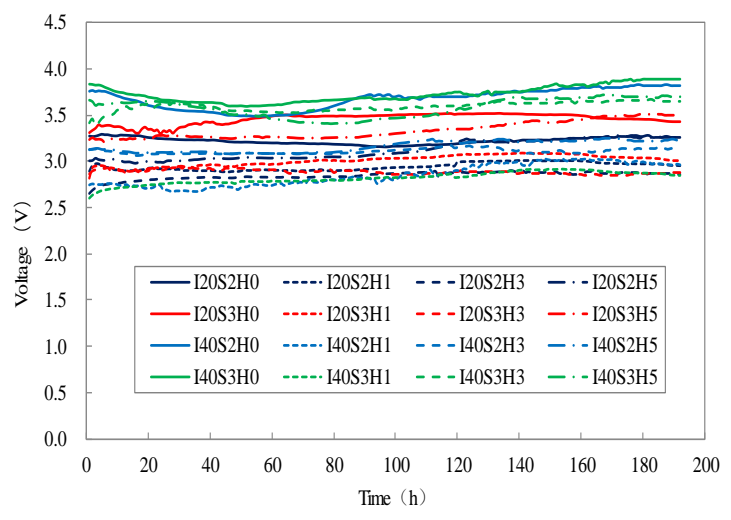

(a) First series

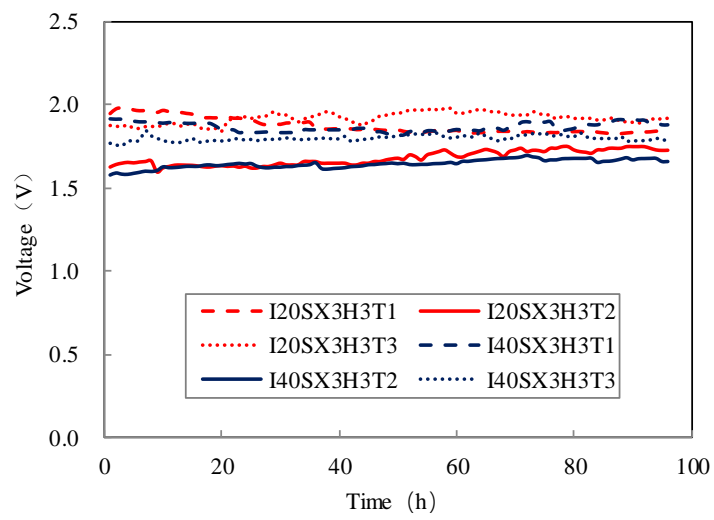

(b) Second series 


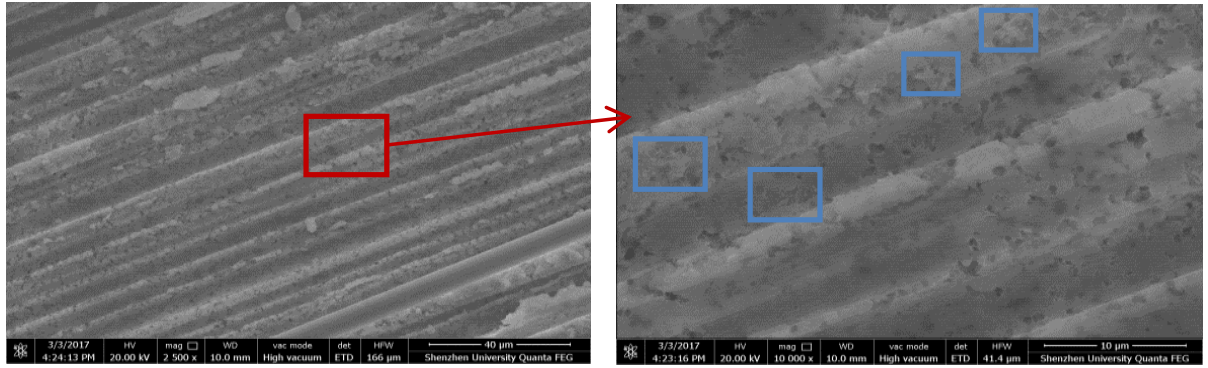

(a) Untreated composite board

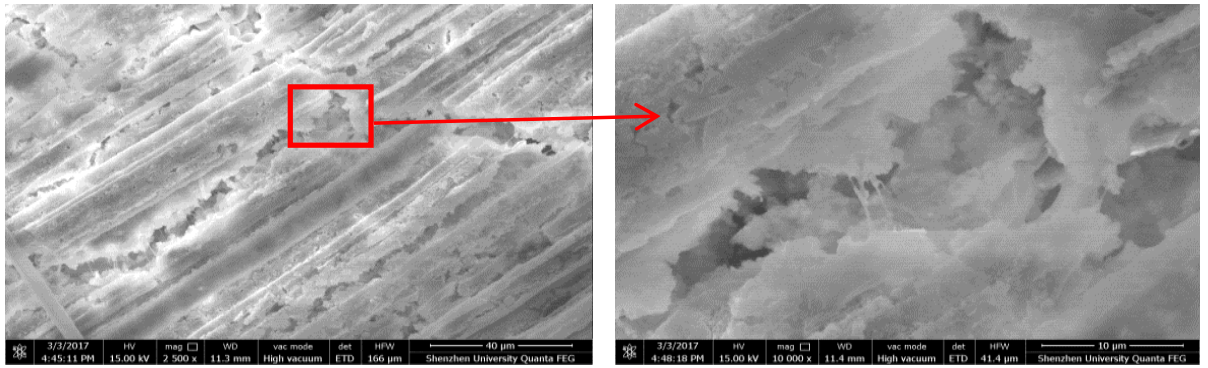

533

(b) Specimen I40S3H1

534

Fig. 5.

535

536

537

538

539

540

541

542

543

544

545

546

(c) Specimen I40S2H3T40

547

Fig. 6 .

548

549

550

551

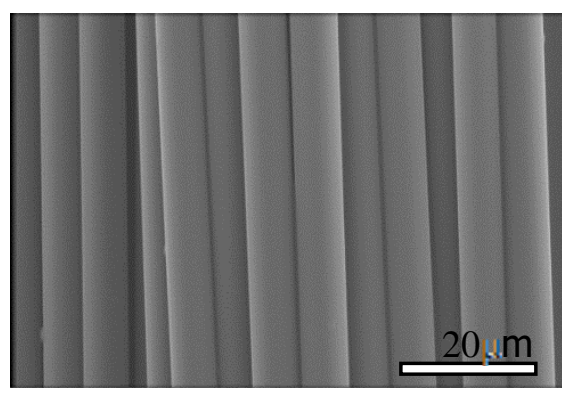

(a) $\mathrm{vCF}$

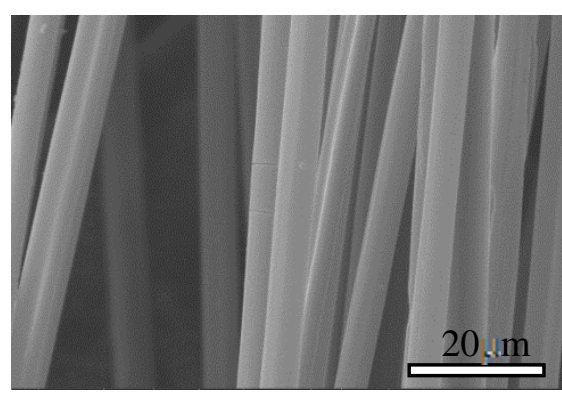

(b) Specimen I40S2H3

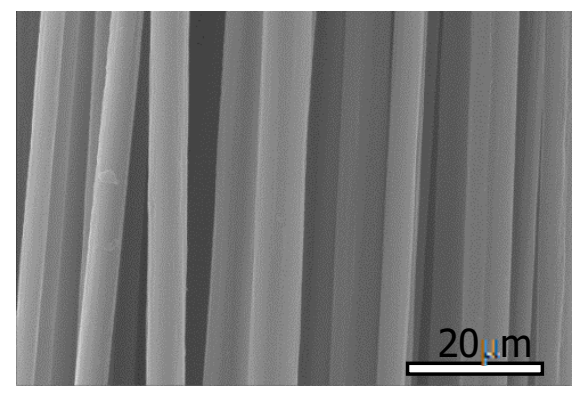


555

556

557

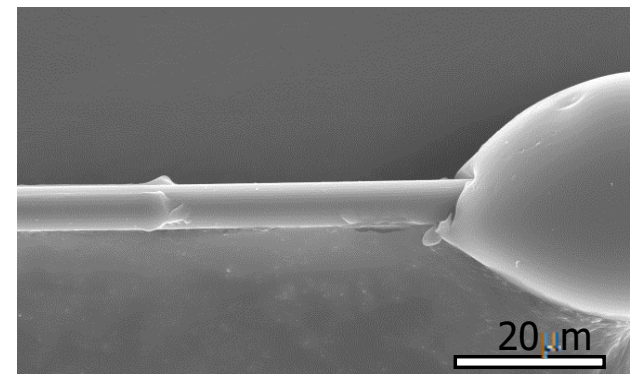

(a) $\mathrm{DB}(\mathrm{vCF})$

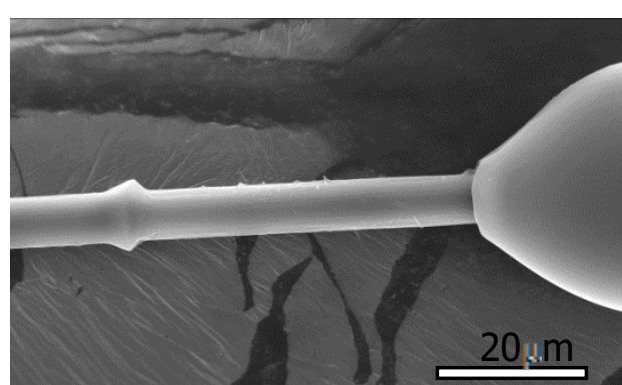

(b) $\mathrm{CB}$ (I20S2H3)

558

Fig. 7.

559

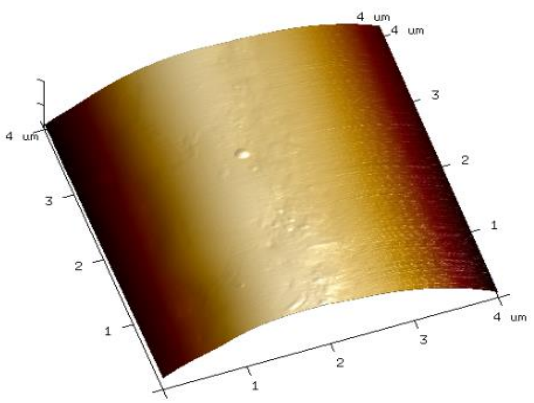

(a) $\mathrm{vCF}$

560

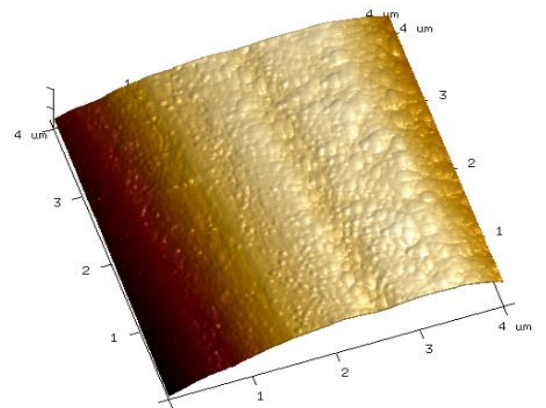

(c) I20S2H3T40

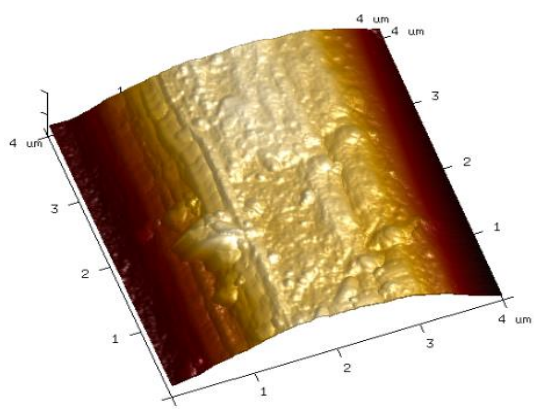

(b) $\mathrm{I} 20 \mathrm{~S} 2 \mathrm{H} 3$

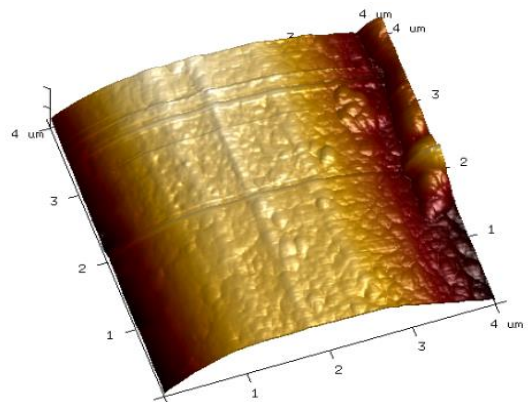

(d) I20S2H3T60

561

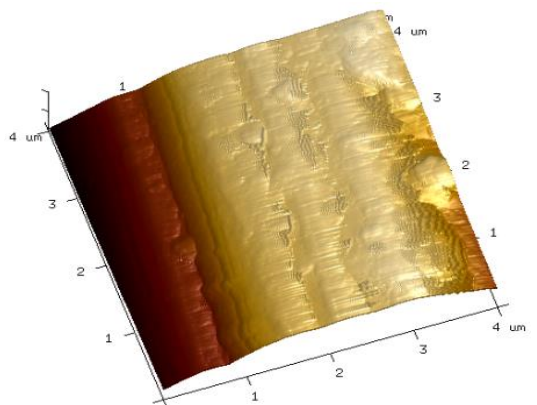

562

(e) I20S2H3T75

Fig. 8. 


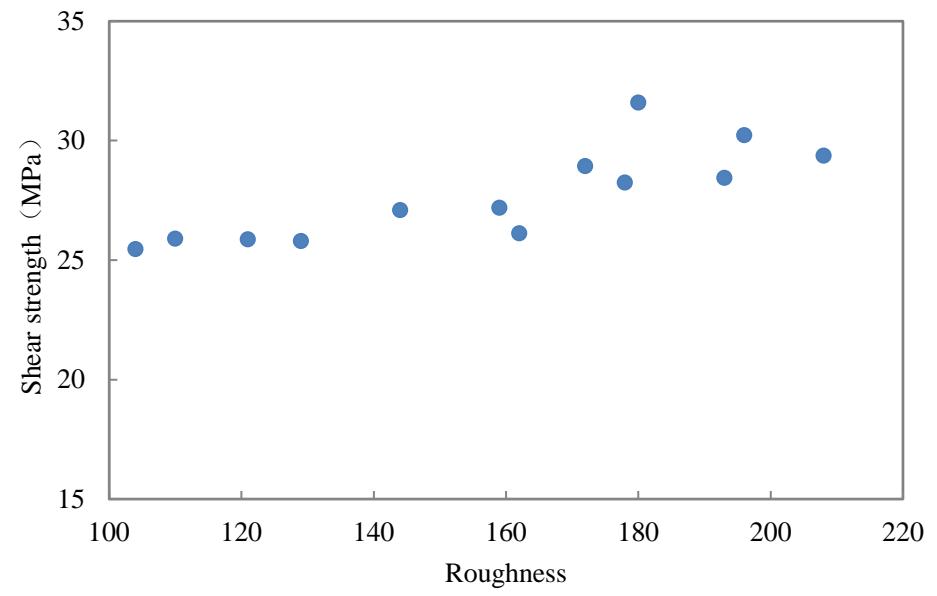

Fig. 9.

565

566

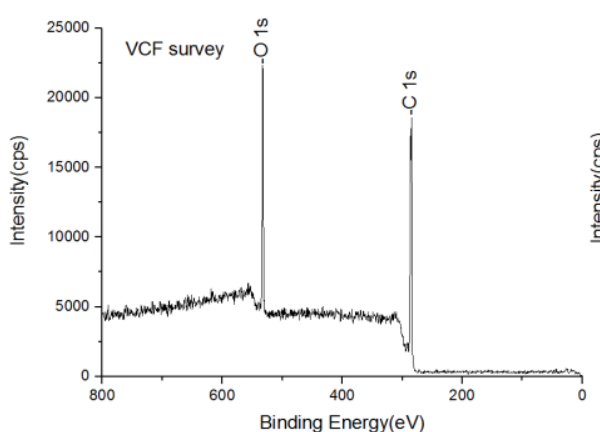

(a) Full spectrum of the

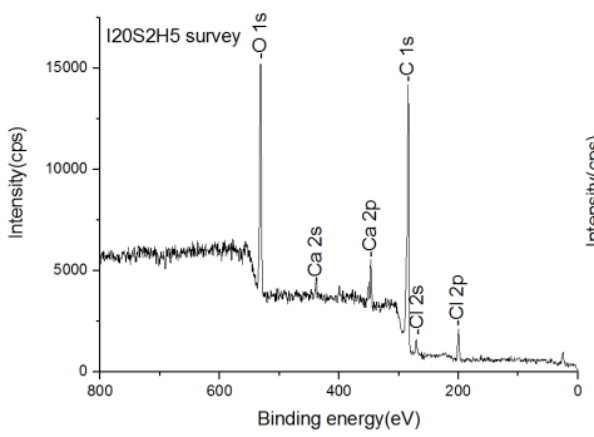

(c) Full spectrum of the rCFs

567

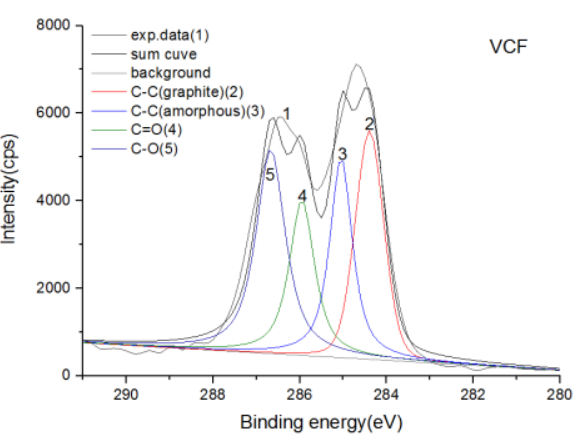

(b) Narrow spectrum of the

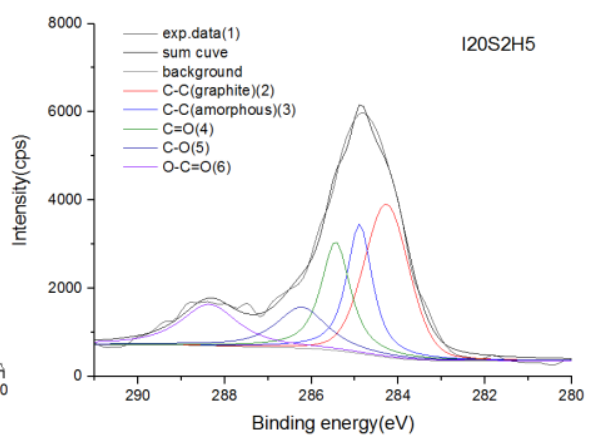

(d) Narrow spectrum of the rCFs from I20S2H5 


\section{List of tables}

570 Table 1. Composition of the cementitious material

571 Table 2. Specimens in the first series of tests

572 Table 3. Specimens in the first series of tests

573 Table 4. Hardness values of the composites after electrochemical reaction, and the number of rCFs

574 Table 5. Mechanical properties of the rCFs obtained from testing

575 Table 6. Elements and functional groups on the surfaces of the rCFs obtained from testing

576

577

578

579

580

581

582

583

584

585

586

587

588

589

590

591

592

593

594

595

596

597 


\begin{tabular}{ccccccc}
\hline Cement & $\begin{array}{c}\text { Silicon } \\
\text { powder }\end{array}$ & $\begin{array}{c}\text { High-molecular } \\
\text { polymer }\end{array}$ & chopped CFs & $\begin{array}{c}\text { Defoaming } \\
\text { agents }\end{array}$ & Superplasticizer & Water \\
\hline 51.49 & 5.72 & 11.44 & 5.15 & 0.28 & 0.17 & 25.75 \\
\hline
\end{tabular}

599

600

601

Table 2.

\begin{tabular}{|c|c|c|c|}
\hline Specimens & Current (mA) & $\mathrm{NaCl}(\%)$ & $\mathrm{HNO}_{3}(\mathrm{~g} / \mathrm{L})$ \\
\hline $\mathrm{I} 20 \mathrm{~S} 2 \mathrm{H} 0$ & 20 & 2 & 0 \\
\hline $\mathrm{I} 20 \mathrm{~S} 2 \mathrm{H} 1$ & 20 & 2 & 1 \\
\hline I20S2H3 & 20 & 2 & 3 \\
\hline I20S2H5 & 20 & 2 & 5 \\
\hline $\mathrm{I} 20 \mathrm{~S} 3 \mathrm{H} 0$ & 20 & 3 & 0 \\
\hline I20S3H1 & 20 & 3 & 1 \\
\hline I20S3H3 & 20 & 3 & 3 \\
\hline I20S3H5 & 20 & 3 & 5 \\
\hline I40S2H0 & 40 & 2 & 0 \\
\hline I40S2H1 & 40 & 2 & 1 \\
\hline I40S2H3 & 40 & 2 & 3 \\
\hline I40S2H5 & 40 & 2 & 5 \\
\hline $\mathrm{I} 40 \mathrm{~S} 3 \mathrm{H} 0$ & 40 & 3 & 0 \\
\hline $\mathrm{I} 40 \mathrm{~S} 3 \mathrm{H} 1$ & 40 & 3 & 1 \\
\hline $\mathrm{I} 40 \mathrm{~S} 3 \mathrm{H} 3$ & 40 & 3 & 3 \\
\hline I40S3H5 & 40 & 3 & 5 \\
\hline
\end{tabular}

602

603

604

605 
Table 3.

\begin{tabular}{lcccc}
\hline Specimens & Current $(\mathrm{mA})$ & $\mathrm{NaCl}(\%)$ & $\mathrm{HNO}_{3}(\mathrm{~g} / \mathrm{L})$ & Temperature $\left({ }^{\circ} \mathrm{C}\right)$ \\
\hline I20S2H3T40 & 20 & 2 & 3 & 40 \\
I20S2H3T60 & 20 & 2 & 3 & 60 \\
I20S2H3T75 & 20 & 2 & 3 & 75 \\
\hline I40S2H3T40 & 40 & 2 & 3 & 40 \\
I40S2H3T60 & 40 & 2 & 3 & 60 \\
I40S2H3T75 & 40 & 2 & 3 & 75 \\
\hline
\end{tabular}

607

608

609

610

611

612

613

614

615

616

617

618

619

620

621

622

623

624

625

626

627 


\begin{tabular}{|c|c|c|c|}
\hline Specimens & Mass of rCFs (mg) & Compared to vCFs (\%) & Hardness \\
\hline $\mathrm{vCF}$ & 841 & --- & --- \\
\hline $\mathrm{I} 20 \mathrm{~S} 2 \mathrm{H} 0$ & 0 & 0 & $\mathrm{HB}$ \\
\hline $\mathrm{I} 20 \mathrm{~S} 2 \mathrm{H} 1$ & 233 & 27.71 & $5 \mathrm{~B}$ \\
\hline $\mathrm{I} 20 \mathrm{~S} 2 \mathrm{H} 3$ & 598 & 71.11 & $9 \mathrm{~B}$ \\
\hline $\mathrm{I} 20 \mathrm{~S} 2 \mathrm{H} 5$ & 516 & 61.36 & $<<9 B$ \\
\hline $\mathrm{I} 20 \mathrm{~S} 3 \mathrm{H} 0$ & 0 & 0 & $2 \mathrm{~B}$ \\
\hline $\mathrm{I} 20 \mathrm{~S} 3 \mathrm{H} 1$ & 512 & 60.88 & $7 \mathrm{~B}$ \\
\hline $\mathrm{I} 20 \mathrm{~S} 3 \mathrm{H} 3$ & 591 & 70.27 & $9 \mathrm{~B}$ \\
\hline $\mathrm{I} 20 \mathrm{~S} 3 \mathrm{H} 5$ & 494 & 58.74 & $<<9 B$ \\
\hline $\mathrm{I} 40 \mathrm{~S} 2 \mathrm{H} 0$ & 0 & 0 & $2 \mathrm{~B}$ \\
\hline $\mathrm{I} 40 \mathrm{~S} 2 \mathrm{H} 1$ & 286 & 34.01 & $9 \mathrm{~B}$ \\
\hline $\mathrm{I} 40 \mathrm{~S} 2 \mathrm{H} 3$ & 574 & 68.25 & $9 \mathrm{~B}$ \\
\hline $\mathrm{I} 40 \mathrm{~S} 2 \mathrm{H} 5$ & 496 & 58.98 & $<<9 \mathrm{~B}$ \\
\hline $\mathrm{I} 40 \mathrm{~S} 3 \mathrm{H} 0$ & 0 & 0 & $5 \mathrm{~B}$ \\
\hline $\mathrm{I} 40 \mathrm{~S} 3 \mathrm{H} 1$ & 483 & 57.43 & $9 \mathrm{~B}$ \\
\hline $\mathrm{I} 40 \mathrm{~S} 3 \mathrm{H} 3$ & 565 & 67.18 & $9 \mathrm{~B}$ \\
\hline I40S3H5 & 485 & 57.67 & $<<9 B$ \\
\hline I20S2H3T40 & 772 & 91.80 & $<<9 B$ \\
\hline I20S2H3T60 & 688 & 81.81 & $<<9 \mathrm{~B}$ \\
\hline I20S2H3T75 & 665 & 79.07 & $<<9 \mathrm{~B}$ \\
\hline I20S2H3T40 & 841 & 77.65 & $<<9 \mathrm{~B}$ \\
\hline I20S2H3T60 & 653 & 75.03 & $<<9 \mathrm{~B}$ \\
\hline I20S2H3T75 & 631 & 72.89 & $<<9 \mathrm{~B}$ \\
\hline \multicolumn{4}{|c|}{ Note: The hardness levels of the pencil hardness tester (from low to high) are as follows: 9B-8B-7B-6B } \\
\hline 5B-4B-3B- & $-\mathrm{H}-2 \mathrm{H}-3 \mathrm{H}-4 \mathrm{H}-5 \mathrm{I}$ & & \\
\hline
\end{tabular}




\begin{tabular}{|c|c|c|c|c|c|c|c|}
\hline Specimens & $\begin{array}{c}\text { Tensile } \\
\text { strength } \\
(\mathrm{MPa})\end{array}$ & $\begin{array}{c}\text { Compared } \\
\text { to } \mathrm{vCF} \\
(\%)\end{array}$ & $\begin{array}{c}\text { IFSS } \\
(\mathrm{MPa})\end{array}$ & $\begin{array}{c}\text { Compared } \\
\text { to vCF } \\
(\%)\end{array}$ & $\begin{array}{c}\text { Failure } \\
\text { modes }\end{array}$ & $\begin{array}{c}\text { Droplet } \\
\text { diameter } \\
(\mu \mathrm{m})\end{array}$ & $\begin{array}{c}\text { Average } \\
\text { roughness } \\
(\mathrm{Ra}) / \mathrm{nm}\end{array}$ \\
\hline $\mathrm{vCF}$ & 3588 & - & 27.09 & 100 & DB & $46.12-51.35$ & 144 \\
\hline I20S2H1 & 3072 & 85.62 & 31.58 & 116.57 & DB & $44.68-50.32$ & 180 \\
\hline I20S2H3 & 2974 & 82.89 & 29.37 & 108.42 & $\mathrm{CB}$ & $42.26-51.09$ & 208 \\
\hline I20S2H5 & 2391 & 66.64 & 25.46 & 93.98 & $\mathrm{CB}$ & $43.68-51.03$ & 104 \\
\hline I20S3H1 & 3001 & 83.64 & 28.44 & 104.98 & DB & $46.12-50.85$ & 193 \\
\hline I20S3H3 & 2898 & 80.76 & 30.22 & 111.55 & $\mathrm{CB}$ & $46.95-50.85$ & 196 \\
\hline I20S3H5 & 2301 & 64.13 & 25.90 & 95.61 & $\mathrm{CB}$ & $42.34-50.54$ & 110 \\
\hline I40S2H1 & 3049 & 84.98 & 28.24 & 104.25 & DB & $43.81-50.73$ & 178 \\
\hline $\mathrm{I} 40 \mathrm{~S} 2 \mathrm{H} 3$ & 2953 & 82.30 & 26.12 & 96.42 & $\mathrm{CB}$ & $42.57-47.30$ & 162 \\
\hline I40S2H5 & 2260 & 62.99 & 25.87 & 95.50 & $\mathrm{CB}$ & $43.34-50.85$ & 121 \\
\hline I40S3H1 & 2987 & 83.25 & 28.93 & 106.79 & DB & $48.49-51.81$ & 172 \\
\hline I40S3H3 & 2944 & 82.05 & 27.18 & 100.33 & $\mathrm{CB}$ & $42.57-49.67$ & 159 \\
\hline I40S3H5 & 2162 & 60.26 & 25.79 & 95.20 & $\mathrm{CB}$ & $42.57-44.94$ & 129 \\
\hline I20H3S2T40 & 2965 & 82.64 & 22.78 & 84.09 & DB & $42.64-47.32$ & 134 \\
\hline I20H3S2T60 & 3118 & 86.90 & 28.45 & 105.02 & DB & $42.57-49.67$ & 168 \\
\hline I20H3S2T75 & 3214 & 89.58 & 25.11 & 92.69 & DB & $45.68-50.86$ & 184 \\
\hline I40H3S2T40 & 2881 & 80.30 & 23.51 & 86.78 & DB & $41.39-49.67$ & 149 \\
\hline I40H3S2T60 & 2949 & 82.19 & 26.75 & 98.74 & $\mathrm{CB}$ & $44.94-52.03$ & 169 \\
\hline I40H3S2T75 & 2960 & 82.50 & 24.29 & 89.66 & DB & $43.76-48.49$ & 192 \\
\hline
\end{tabular}

$63 \overline{3}$

634

635

636 


\begin{tabular}{lcccccccccccccc}
\hline Specimens & $\mathrm{C}$ & $\mathrm{O}$ & $\mathrm{Cl}$ & $\mathrm{N}$ & $\mathrm{Si}$ & $\mathrm{Ca}$ & $\mathrm{O} / \mathrm{C}$ & $\mathrm{C}-\mathrm{C}^{1}$ & $\mathrm{C}-\mathrm{C}^{2}$ & $\mathrm{C}=\mathrm{O}$ & $\mathrm{C}-\mathrm{O}$ & $\mathrm{C}-\mathrm{Cl}$ & $\mathrm{O}-\mathrm{C}=\mathrm{O}$ \\
\hline vCF & 79.3 & 20.7 & 0 & 0 & 0 & 0 & 0.261 & 27.3 & 23.8 & 19.9 & 29 & 0 & 0 \\
I20S2H1 & 68.2 & 25.2 & 1.4 & 0 & 3.4 & 1.8 & 0.370 & 34.4 & 18.4 & 15.8 & 18.8 & 0 & 12.6 \\
I20S2H3 & 69.7 & 26.9 & 2.5 & 0 & 0 & 0.9 & 0.386 & 32.7 & 16.7 & 17.5 & 16.5 & 0 & 16.6 \\
I20S2H5 & 69.1 & 25.9 & 2.4 & 0 & 0 & 2.6 & 0.375 & 32.3 & 16.1 & 18.8 & 17.2 & 0 & 15.6 \\
I20S2H3T40 & 66.8 & 28.4 & 4.8 & 0 & 0 & 0 & 0.425 & 28.3 & 16.6 & 16.8 & 12.5 & 8.2 & 17.7 \\
I20S2H3T60 & 64.6 & 27.7 & 2.4 & 2.8 & 1.8 & 0.6 & 0.429 & 22.9 & 22.0 & 20.6 & 18.3 & 0 & 16.2 \\
I20S2H3T75 & 63.7 & 25.9 & 1.9 & 5.2 & 2.6 & 0.7 & 0.407 & 29.9 & 21.5 & 19.7 & 13.6 & 0 & 15.3 \\
\hline
\end{tabular}

638

639 